\title{
Application and Effect Evaluation of 'Five Routine Working Regulation' Method in Nursing Quality Management of Outpatient Injection Room
}

\author{
Xiaoxia Liu, Guohua Huang* \\ Central Injection Room, The First Affiliated Hospital, Jinan University, Guangzhou, China \\ Email address: \\ 191746135@qq.com (Xiaoxia Liu),jndxhgh@163.com(Guohua Huang) \\ ${ }^{*}$ Corresponding author
}

To cite this article:

Xiaoxia Liu, Guohua Huang. Application and Effect Evaluation of 'Five Routine Working Regulation' Method in Nursing Quality Management of Outpatient Injection Room. Science Journal of Clinical Medicine. Vol. 9, No. 2, 2020, pp. 34-36. doi: 10.11648/j.sjcm.20200902.13

Received: April 30, 2020; Accepted: May 22, 2020; Published: May 29, 2020

\begin{abstract}
Objective: To assess application and effect evaluation of 'Five Routine Working Regulation' method in nursing quality management of outpatient injection room. Methods: We invested 16 nurses and 200 patients to join our study in treatment process. Additionally, we grouped the data accord to different time periods. The time periods of control group are from July 2017 to June 2018, we did not implement 'Five Routine Working Regulation' method in this time period. The time periods of intervention group are from July 2018 to June 2019, we implement 'Five Routine Working Regulation' method in this time period. Our researchers collected the information include the quality indicators, nurse satisfaction and patient satisfaction. Result: In the quality indicators research, intervention group participants have better performance than that of control group in this study. In particular, the intervention group has not cases in Total number of no-write opening time of sterile articles in use and Total number of expired or waste of medicine and substance. But the control group has cases in those two domains ( 0 vs 25,0 vs 210$)$. In nurse satisfaction research, the result indicate intervention group has better nurse satisfaction assessment in our research result $(87.5 \%$ vs $62.5 \%)$. In patient satisfaction, the intervention group patients provide more good assessment in satisfaction research, and the result is statistical significance $(190 \mathrm{vs} 171, \mathrm{p}=0.012)$. Conclusion: the 'Five Routine Working Regulation' method has influence to improve the nursing quality in outpatient injection room.
\end{abstract}

Keywords: Nursing Quality, Outpatient Injection Room, Satisfaction

\section{Introduction}

Nurses is key personnel in healthcare delivery, their work include prevention of adverse events, the provision and coordination of care, and optimization of health service productivity and patient outcomes [1]. They often need to measure, monitor and report on the appropriateness and effectiveness of healthcare, informing improvements in healthcare quality [2]. Also, the Nurses Responsibilities include consumer-centered care through systems and processes that support shared decision making, continuity of care, open disclosure, and sensitivity to the cultural needs and health literacy of patients [3]. In the healthcare quality, Healthcare quality is a major driver of innovation, growth, and competitiveness. from a managerial perspective, healthcare quality is a key source of business dynamism, innovation, and improvements in the social ecosystem [4, 5]. Base on United States' report, healthcare spending represented approximately $19 \%$ of the gross domestic product in 2016 [6]. New technology and its broad adoption into the healthcare industry are considered two of the main contributors to this spending increase [7].

'Five Routine Working Regulation' method is a fast and effective management method for units or organizations to improve quality environment, improve safety and work efficiency, reduce the incidence of failures, and improve the social image and competitiveness of units or organizations [8]. 'Five Routine Working Regulation' method include 5 parts, such as Structurise, Systematise, Sanitise, Standardise, and Self-discipline [9]. The aim of our study is that assess 
application and effect evaluation of 'Five Routine Working Regulation' method in nursing quality management of outpatient injection room.

\section{Methods}

\subsection{Participants Enrollment and Survey Methods}

We invested 16 nurses and 200 patients to join our study in treatment process. Additionally, we grouped the data accord to different time periods. The time periods of control group are from July 2017 to June 2018, we did not implement 'Five Routine Working Regulation' method in this time period. The time periods of intervention group are from July 2018 to June 2019, we implement 'Five Routine Working Regulation' method in this time period. Our researchers collected the information include the quality indicators, nurse satisfaction and patient satisfaction. The information is collected by interview, record and simple questionnaire.

In our study, the measure of 'Five Routine Working Regulation' method include 5 domains. In structurise domain, we organize to learn relevant knowledge in daily, establish relevant quality assessment standards, and analyze the problems encountered. In systematize domain, each functional area is managed by specially-assigned personnel, who shall check and clean once a month. Also, we add 2 mobile nurses in peak period of patient. In sanitise domain, we make clean on a monthly and daily basis. In standardise domain, we set the goal of improving the quality of care for the development of related work. In self-discipline domain, nurses were asked to form good habits in their daily work.

Their inclusion criteria were: (1) Patients volunteered to participate our study in treatment; (2) Nurses volunteered to participate our study. Their withdraw criteria were: (1) The patients have not normal mental state; (2) The patients are unable to concentrate.

\subsection{Statistical Analysis}

Our data analyzer performed the statistical analysis by SPSS 22.0. The $\mathrm{P}$ value, t-test and chi-square test were associated with collection result were analyzed. Besides, the mean standard deviation for statistical description.

\section{Result}

The quality indicators contain 5 domains, such as Total number of no-write opening time of sterile articles in use, Total number of expired or waste of medicine and substance, Medical waste classification's pass rate, Item placement specification rate, and Save items rate (Table 1). In the quality indicators research, intervention group participants have better performance than that of control group in this study. In particular, the intervention group has not cases in Total number of no-write opening time of sterile articles in use and Total number of expired or waste of medicine and substance. But the control group has cases in those two domains ( 0 vs 25 , 0 vs 210).

Table 1. Quality Indicators.

\begin{tabular}{lllll}
\hline Projects & $\begin{array}{l}\text { Total number of no-write } \\
\text { opening time of sterile } \\
\text { articles in use }\end{array}$ & $\begin{array}{l}\text { Total number of expired or } \\
\text { waste of medicine and } \\
\text { substance }\end{array}$ & $\begin{array}{l}\text { Medical waste } \\
\text { classification's pass } \\
\text { rate (\%) }\end{array}$ & $\begin{array}{l}\text { Item placement } \\
\text { specification rate } \\
(\%)\end{array}$ \\
\hline Intervention group & 0 & 0 & $\begin{array}{l}\text { Save items } \\
\text { rate }\end{array}$ & $95 \%$ \\
Control group & 25 & 210 & $90 \%$ & $98 \%$ \\
\hline
\end{tabular}

The nurse satisfaction is collected from interview or simple questionnaire. In Table 2, the result indicate intervention group has better nurse satisfaction assessment in our research result $(87.5 \% \mathrm{vs} 62.5 \%)$.

Table 2. Nurse satisfaction.

\begin{tabular}{lll}
\hline Projects & Nurse number of satisfaction (n) & Percent (\%) \\
\hline Intervention group $(\mathrm{n}=16)$ & 14 & $87.5 \%$ \\
Control group $(\mathrm{n}=16)$ & 10 & $62.5 \%$ \\
$\mathrm{X}^{2}$ & - & \\
$\mathrm{P}$ value & 0.032 & \\
\hline
\end{tabular}

In another satisfaction research, the patient satisfaction also is collected by interview or simple questionnaire. The intervention group patients provide more good assessment in satisfaction research, and the result is statistical significance $(190 \mathrm{vs} 171, \mathrm{p}=$ 0.012).

Table 3. Patient Satisfaction

\begin{tabular}{lll}
\hline Projects & Patient number of satisfaction $(\mathbf{n})$ & Percent $(\%)$ \\
\hline Intervention group $(\mathrm{n}=200)$ & 190 & $95.0 \%$ \\
Control group $(\mathrm{n}=200)$ & 171 & $85.5 \%$ \\
$\mathrm{X}^{2}$ & 6.27 & \\
P value & 0.012 & \\
\hline
\end{tabular}




\section{Discussion and Conclusion}

Despite the universal desire to monitor healthcare quality and substantial international efforts to identify and share best practice in measuring it, our cross-country comparison reveals striking differences in the official indicator sets used by statutory regulators to monitor the quality of hospital care in England, Germany, France, and the Netherlands [10].

The structure, process, and outcome indicators are different in official indicator sets. But Germany stood out for almost entirely eschewing structure measures in favour of outcome and process ones. In other country, regulators in the other countries used all three indicator types more freely, with outcome indicators predominating in England, process indicators in France, and Dutch indicators evenly divided between Donabedian's three styles of measurement [11]. In addition, to improve the consistency, reliability, and validity of care quality metrics, the World Health Organization, European Commission, OECD, and Institute of Medicine have published alternative frameworks for defining key indicator sets [12-15].

According to above result, the 'Five Routine Working Regulation' method has influence to improve the nursing quality in outpatient injection room. The data contains 3 domains, such as quality indicators, nurse satisfaction and patient satisfaction. In quality indicators research, 'Total number of no-write opening time of sterile articles in use' and 'Total number of expired or waste of medicine and substance' have big gap in different between intervention group and control group. It indicates 'Five Routine Working Regulation' method can influence those two domains. Another 3 domains are similar in our study, it indicates 'Five Routine Working Regulation' method has weak effect to those 3 domains. In nurse satisfaction and patient satisfaction, it shows the satisfaction of 2 important roles in treatment process, those 2 roles can influence the outcome of treatment outcome in outpatient injection room. In the result, the better assessments are more in intervention group compare with control group. However, the sample size is limit the result in our study so that the gap between the two sets of data is not obvious.

\section{References}

[1] Aiken LH, Sloane DM, Bruyneel L, et al. Nurse staffing and education and hospital mortality in nine European countries: A retrospective observational study. Lancet. 2016; 383 (9931): $1824-1830$
[2] Australian Commission on Safety and Quality in Healthcare. Clinical governance for nurses and midwives. Sydney: ACSQHC. 2017.

[3] Canadian Nurses Association. Framework for the practice of registered nurses in Canada. Ottawa. 2015.

[4] Slater P, McCance T, McCormack B. The development and testing of the Person-centred Practice Inventory - Staff (PCPI-S). International Journal for Quality in Health Care. 2017; 29 (4): 541-547.

[5] Ancarani A, Di Mauro C, Gitto S, Mancuso P, Ayach A. Technology acquisition and efficiency in Dubai hospitals. Technol. Forecast. Soc. Chang. 2016; 113: 475-485.

[6] Berwick DM, Hackbarth AD. Eliminating waste in US health care. JAMA. 2017; 307 (14): 1513-1516.

[7] Bessant J, Künne C, Möslein K. Opening Up Healthcare Innovation: Innovation Solutions for a 21 st Century Healthcare System. 2015.

[8] Lishan X, Xiaoxia L, Lina C. Study on the application of five routine working regulations in the improvement of drug supply management during the infusion in the primary hospitals. Nursing Practice and Research. 2018; 15 (11): 109-110.

[9] Yake G, Guihua L, Xiaojuan L, Lin Y. Application of "Five Routine Working Regulation" in the Management of Pharmacy Cold Chain. 2018; 32 (09): 1297-1300.

[10] Järvelin J, Häkkinen U. Can patient injury claims be utilised as a quality indicator? Health Policy 2016; 104 (2): 155-62.

[11] Cashin A, Heartfield M, Bryce J, Devey L, Buckley T, Cox D, et al. Standards for practice for registered nurses in Australia. Collegian. 2017; 24: 255-266.

[12] Groene O, Skau JKH, Frølich A. An international review of projects on hospital performance assessment. International Journal for Quality in Health Care. 2018; 20 (3): 162-171.

[13] Beaussier A-L, Demeritt D, Griffiths A, Rothstein H. Accounting for failure: risk-based regulation and the problems of ensuring healthcare quality in the NHS. Health, Risk \& Society 2016; 18 (3-4): 205-224.

[14] Carinci F, Van Gool K, Mainz J, Veillard J, Pichora EC, Januel $\mathrm{JM}$, et al. Towards actionable international comparisons of health system performance: expert revision of the OECD framework and quality indicators. International Journal for Quality in Health Care. 2015; 27 (2): 137-146.

[15] Griffiths A, Leaver MP. Wisdom of patients: predicting the quality of care using aggregated patient feedback. BMJ Quality Safety. 2018; 27 (2): 110-118. 